\title{
Lipolysis Induced by Segment Wall Extract from Satsuma Mandarin Orange (Citrus unshu Mark)
}

\author{
Takahiro TsUJITA and Takeshi TAKAKU \\ Bioscience, Integrated Center for Sciences, Ehime University, Shitsukawa, Toon, Ehime 791-0295, Japan \\ (Received April 27, 2007)
}

\begin{abstract}
Summary The lipolysis induced by Satsuma mandarin orange (Citrus unshu Mark) was investigated using rat fat cells. Peel or segment wall extract from Satsuma mandarin orange induced the lipolysis in a concentration-dependent manner, whereas juice sac extract did not induce the lipolysis. High concentration of synephrine, which is an adrenergic amine, was detected in the peel or segment wall extract, whereas it was not detected in the juice sac extract. The segment wall extracts from Iyokan and orange had high lipolytic activity, whereas the extracts from grapefruit and lemon did not have lipolytic activity. The $\beta$-antagonist inhibited the lipolysis elicited by the segment wall extract from Satsuma mandarin orange, whereas $\alpha$-antagonist did not inhibit the lipolysis induced by the segment wall. The lipolysis induced by the segment wall was considerably higher in the visceral fat cells when compared to the subcutaneous fat cells. These results suggest that the segment wall, an edible fraction, from Satsuma mandarin orange might be useful as a functional food, especially as a fat-reducing material.
\end{abstract}

Key Words citrus fruits, segment wall, lipolysis, fat cells, synephrine

Obesity is a social health problem and is associated with risk factors such as hyperlipidemia, type 2 diabetes mellitus and hypertension. The problem does not only affect developed countries, but also throughout developing countries, there is now a significant increase in overweight. Many dietary supplements have been marketed for weight loss in order to avoid these risk factors. The extracts of Citrus aurantium (Seville orange or sour orange) have been introduced for anti-obesity treatment (1-3). The dried, entire unripe fruit of $C$. aurantium is used in herbal medicine primarily to treat digestive problems. It is called "Kijitsu" in Japanese. Usually, C. aurantium extracts from unripe peel are used as weight-loss aids and they contain adrenergic amines such as synephrine and octopamine (4). Synephrine is the main active constituent of the extract; it elevates the lipid metabolism since it stimulates lipolysis (5). It is also well known that the amines found in $C$. aurantium fruit extract have effects on the cardiovascular system through adrenergic stimulation (6). In this paper, we discovered that the peel or segment wall from the ripe Satsuma mandarin orange contains biological amines and stimulates the lipolysis in fat cells. The peel and segment wall are generated in large quantities as waste

E-mail: tsujita@m.ehime-u.ac.jp

Abbreviations: TES, N-tris(hydroxylmethyl)methyl-2-aminoethanesulfonic acid.

Botanical name: Satsuma mandarin orange, Ehime nakate (Citrus unshu Mark); Iyokan, Miyauchi iyo (Citrus iyo Hort ex Tanaka); Buntan, Tosa-Buntan (Citrus grandis (L) Osbeck); Hassaku, Citrus hassaku Hort ex Tanaka; Natsumikan, Citrus natsudaidai Hayata; orange, Citrus sinensis (L) Osbeck; grapefruit, Citrus pradisi Mocf.; lemon, Citras limon (L) Burm. products during squeezing the Satsuma mandarin orange fruits. For effective use of these waste products, the lipolytic activity of the segment wall from Satsuma mandarin orange was compared with other citrus fruits.

\section{MATERIALS AND METHODS}

Materials. Citrus fruits were obtained from Ehime Fruit Tree Experiment Station. Collagenase (type IV) was purchased from Worthington Biochemical Corp. (Freehold, NJ). Bovine serum albumin was purchased from Wako Pure Chemical Industries, Ltd. (Osaka, Japan). Albumin was extracted by the method of Chen (7) to remove the free fatty acids.

Extract from citrus fruits. The peel or segment wall from citrus fruits was lyophilized and $200 \mathrm{mg}$ of lyophilized material was added to $6 \mathrm{~mL}$ of methanol. The juice sac $(3 \mathrm{~mL})$ from Satsuma mandarin or marketed fruit juice $(3 \mathrm{~mL})$ was lyophilized and added to $6 \mathrm{~mL}$ of methanol. After sonication of the methanol mixture for $2 \mathrm{~min}$, the suspension was centrifuged at $2,000 \times g$ for 10 min and the upper solution was dried under reduced pressure using a centrifugal vacuum evaporator, Speed Vac SC100A (Savant Co.). Water $(1 \mathrm{~mL})$ was added to the dried material and the mixture was sonicated for 2 min. After adjusting the $\mathrm{pH}$ to 7.0 , the mixture was centrifuged at $2,000 \times g$ for $10 \mathrm{~min}$ and the upper solution was used as the citrus extract.

Measurement of lipolysis in fat cells. Male Crj:Wistar rats weighing 200-250 g were given standard laboratory diets (Oriental Yeast Co., Ltd.) and water ad libitum, and maintained according to the Laboratory Animal Center guidelines at Ehime University School of 
Medicine, on a 12-h (7 am to $7 \mathrm{pm}$ ) light-dark cycle. Isolated fat cells were obtained from epididymal adipose tissues by the method of Rodbell (8). Fat cells $(100 \mu \mathrm{L}$ packed volume) were incubated for $1 \mathrm{~h}$ at $37^{\circ} \mathrm{C}$ in $200 \mu \mathrm{L}$ of Hank's buffer (25 mM TES, pH 7.4 containing $135 \mathrm{~mm} \mathrm{NaCl}, 5 \mathrm{~mm} \mathrm{KCl}$ and $1 \mathrm{mM} \mathrm{MgCl}_{2}$ ) supplemented with $2.5 \%$ bovine serum albumin and $50 \mu \mathrm{L}$ (corresponding to $10 \mathrm{mg}$ dried material) of the citrus extract. The release of FFA was measured as described previously (9). Briefly, the incubation mixture was mixed with $3 \mathrm{~mL}$ chloroform-heptane $(1: 1, \mathrm{v} / \mathrm{v})$ containing $2 \%(\mathrm{v} / \mathrm{v})$ methanol and extracted by shaking the tube horizontally for $10 \mathrm{~min}$ in a shaker. The mixture was centrifuged $(2,000 \times g, 10 \mathrm{~min})$, and the upper aqueous phase removed by suction. Copper reagent $(1 \mathrm{~mL})$ was then added to the lower organic phase. The tube was shaken for $10 \mathrm{~min}$, the mixture was centrifuged $(2,000 \times g, 10 \mathrm{~min})$, and $0.5 \mathrm{~mL}$ of the upper organic phase, which contained the copper salts of the extracted fatty acids, was treated with $0.5 \mathrm{~mL}$ $0.1 \%(\mathrm{w} / \mathrm{v})$ bathocuproine in chloroform containing $0.05 \% \quad(\mathrm{w} / \mathrm{w})$ 3(2)-tert-butyl-4-hydroxyamisole. Its absorbance was then measured at $480 \mathrm{~nm}$. Lipolysis was expressed as microequivalents $(\mu \mathrm{Eq})$ of FFA released per $1 \mathrm{~mL}$ packed volume fat cells per hour.

Measurement of synephrine concentration in the citrus extract. Synephrine concentration in the citrus extract was estimated using a HPLC system (high performance liquid chromatography system, Gulliver, JASCO Co.). The citrus extract $(100 \mu \mathrm{L})$ was applied to TSKgel (ODS$80 \mathrm{TM}, 150 \times 60 \mathrm{~mm}$, TOSOH Co.) equilibrated with water containing 1\% trifluoroacetic acid. Synephrine and octopamine were eluted with the same buffer at an elution rate of $0.5 \mathrm{~mL} / \mathrm{min}$.

Data and statistical analysis. All values are expressed as mean \pm SE. Data were analyzed by ANOVA (nonpaired $t$-test) in Stat View. Values of $p<0.05$ were considered significant.

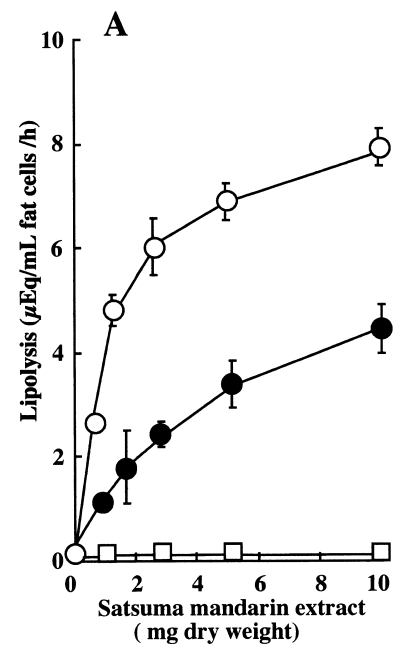

\section{RESULTS AND DISCUSSION}

Lipolytic activities of marketed fruit juices

The lipolysis in fat cells induced by the extracts from marketed fruit juices was measured. Citrus juice extracts induced lipolysis, whereas apple and grape juice extracts did not induce lipolysis (Fig. 1). Other fruit juices such as peach and tomato also did not induce lipolysis (data not shown). It is well known that citrus fruits contain lipolytic amines such as synephrine (5). Synephrine concentration in the extracts from mar-

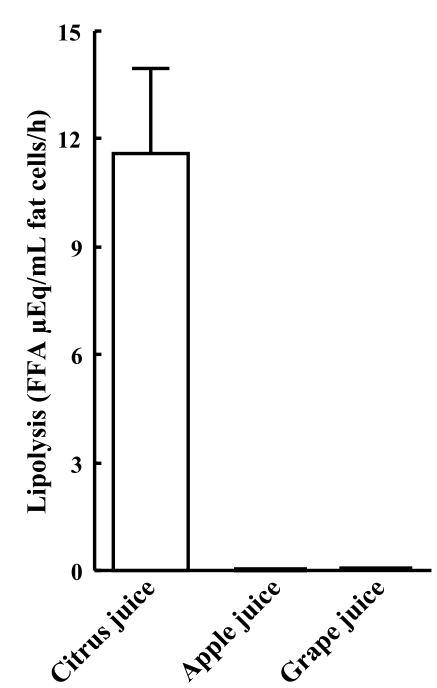

Fig. 1. Lipolytic activities in commercial fruit juices. Lipolysis in rat fat cells induced by marketed fruit juice extracts ( 6 of citrus juices, 5 of apple juices and 4 of grape juices) was determined. Citrus juices were mixtures from several citrus fruit juices such as Satsuma mandarin orange, orange or Iyokan. The results are expressed as mean \pm SE. Values not sharing a letter are significantly different, $p<0.05$.

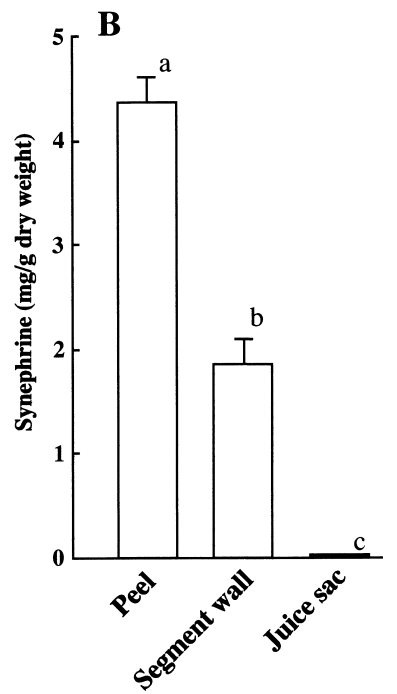

Fig. 2. Effect on lipolysis in fat cell (A) or synephrine concentration (B) from the extracts from Satsuma mandarin orange (Citrus unshu Marc.). The extracts were prepared from peel $(\bigcirc)$, segment wall $(\bullet)$ and juice sac $(\square)$ as described in "Materials and Methods." The results are expressed as mean \pm SE of four experiments. Values not sharing a letter are significantly different, $p<0.05$. 


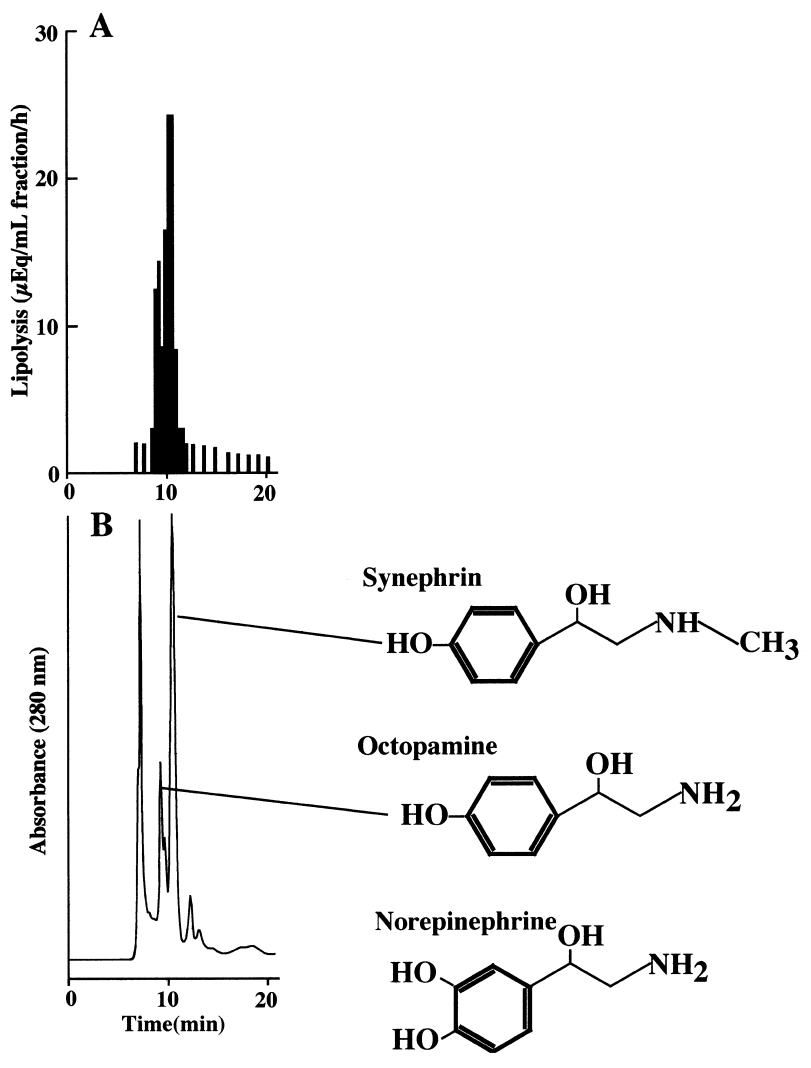

Fig. 3. Typical HPLC chromatogram of the extract from segment wall of Satsuma mandarin orange. (A) Absorbance $280 \mathrm{~nm}$ and (B) lipolytic activity. TSKgel (ODS$80 \mathrm{TM}, 150 \times 60 \mathrm{~mm}$ ) was equilibrated and eluted with water containing $1 \%$ trifluoroacetic acid on flow rate $0.5 \mathrm{~mL} / \mathrm{min}$.

keted fruit juices was determined using a HPLC system. Synephrine was contained at a rate of $21.3 \pm 4.0 \mu \mathrm{g} / \mathrm{mL}$ (12 to $27 \mu \mathrm{g} / \mathrm{mL}$ ) in citrus juices, but it was not detected in apple or grape juices (data not shown).

Lipolytic activities of Satsuma mandarin orange

We investigated the lipolytic activity of ripe Satsuma mandarin orange, which is a typical citrus fruit in Japan. The peel extract from Satsuma mandarin orange induced lipolyisis in a concentration-dependent manner (Fig. 2A). The extract of the segment wall also induced lipolysis in a concentration-dependent manner, about $30 \%$ of the peel extract, but the juice sac extract did not induce lipolysis. Figure 3 shows the HPLC pattern of the segment wall extract from Satsuma mandarin orange. Synephrine was eluted at $10.3 \mathrm{~min}$ and octopamine, which is another lipolytic amine, was eluted at $9.3 \mathrm{~min}$. The lipolytic activity of each fraction coincided with the peaks of these amines (Fig. 3B). The high concentration of synephrine was determined in the peel extract (Fig. 2B). The segment wall extract also contained synephrine, about $30 \%$ of the peel extract, whereas synephrine was not determined in the juice sac extract. Therefore, the synephrine concentration of the extracts agreed with the lipolytic power of these extracts.

Usually, unripe citrus fruits have been introduced for anti-obesity treatment, because it is believed that the unripe citrus fruit contains large amount of biological

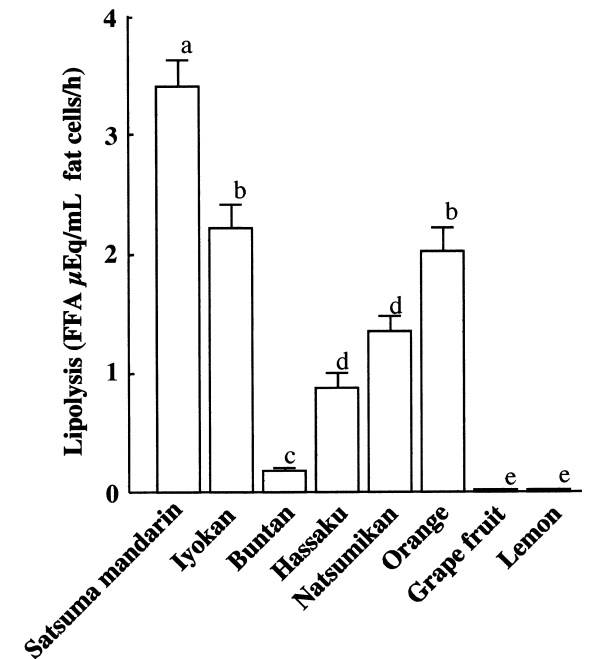

Fig. 4. Effect on lipolysis in fat cell from the extracts from segment walls from various citrus fruits. $50 \mu \mathrm{L}$ (10 mg dry material) of segment wall extracts were incubated with fat cells. The results are expressed as mean $\pm \mathrm{SE}$ of four experiments. Values not sharing a letter are significantly different, $p<0.05$.

amines and these amines decrease with ripening. The extract of unripe Satsuma mandarin orange ( 2 mo after flowering) induced lipolysis; the lipolytic activity of the whole unripe fruit was $36.4 \mu \mathrm{Eq}$ FFA/10 mg dry weight/h, which was higher than that of unripe Citrus aurantium extract (25.7 $\mu \mathrm{Eq}$ FFA/10 mg dry weight/h), which has been used commonly as a weight-loss aid $(10,11)$. The lipolytic activities of the peel and segment wall of the ripe Satsuma mandarin orange were 10.4 and $3.2 \mu \mathrm{Eq} \mathrm{FFA} / 10 \mathrm{mg}$ dry weight/h, respectively. The fruit weight was increased about 13-fold between 2 mo and 6 mo (ripe fruit) after flowering. The weight ratio of peel and segment wall contents of the ripe fruit were about 24 and $7 \%$, respectively. Therefore, the peel and segment wall weight were 3.1-fold and 0.9-fold of the unripe fruit weight, respectively. Total lipolytic activity of the ripe $(10.4 \times 3.1+3.2 \times 0.9)$ fruit was roughly equal to that of the unripe fruit.

Lipolytic activities of the segment wall extracts from various citrus fruits

We determined the lipolytic activities in fat cells induced by the segment wall extracts from various citrus fruits (Fig. 4) because the segment wall is an edible fraction and it might be useful as a functional food. The segment wall extracts from Iyokan and orange had high lipolytic activity, whereas the extracts from grapefruit and lemon did not have lipolytic activity. The lipolytic activities from Hassaku and Natsumikan segment walls took a middle position. Differences similar to those of the lipolytic activity among the citrus fruits were observed for peel extracts and unripe citrus fruit extracts (data not shown). As for the classification of Citrus genus by Tanaka (12), Aurantium Tanaka (including orange, Iyokan and Natsumikan) and Acrumen Tanaka (including Satsuma mandarin orange) tend to have high lipolytic activity, and Limonellus 


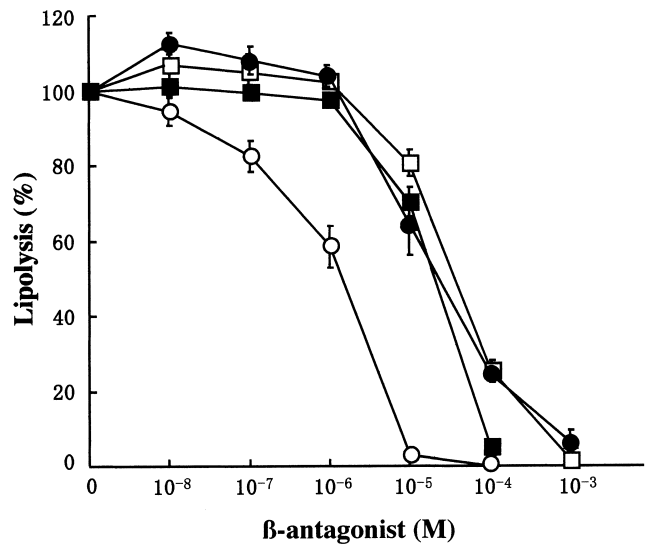

Fig. 5. Effect of $\beta$-antagonists on lipolysis induced by the segment wall extract from Satsuma mandarin orange. $50 \mu \mathrm{L}$ (10 mg dry material) of segment wall extracts were incubated with fat cells. Propranolol $\left(\beta_{1^{-}}, \beta_{2^{-}}\right.$and $\beta_{3}$-antagonist, $\left.\bigcirc\right)$, atenolol ( $\beta_{1}$-antagonist, $\square$ ), ICI118551 ( $\beta_{2}$-antagonist, $\left.\mathbf{\square}\right)$ and SR59230A $\left(\beta_{3}\right.$-antagonist, $\bullet$ ). The results are expressed as mean \pm SE of four experiments.

Tanaka (including lemon) and Cephalocitrus Tanaka (including Bunntan, Hassaku and Grapefruit) tend to have the low lipolytic activity. Further experiments need to determine this tendency.

Lipolytic activities of segment walls from Satsuma mandarin orange

It is well known that the $\beta$-blocker inhibits the lipolysis in fat cells induced by biological amines such as norepinephrine. Figure 5 shows the effect of $\beta$-blockers on lipolysis induced by the segment wall extract from Satsuma mandarin orange. Selective $\beta$-antagonists $(\beta 1-, \beta 2-$, and $\beta 3-)$ inhibited the lipolysis induced by the segment wall extract in a concentration-dependent manner, and the inhibition patterns were almost the same. A non-selective $\beta$-antagonist, propranolol, at a concentration of $10^{-5} \mathrm{M}$ completely inhibited the lipolysis elicited by the segment wall extract, whereas $\alpha$ antagonist phenoxybenzamine did not inhibit the lipolysis up to $10^{-3} \mathrm{M}$ (data not shown). These results suggest that the segment wall extract from Satsuma mandarin orange is nonselective $\beta$-agonist. The mechanism of catecholamine ( $\beta$-agonist)-induced lipolysis in fat cells has been explained in the cyclic AMP-protein kinase cascade $(13,14)$. According to this cascade, catecholamine stimulates adenylate cyclase in fat cell membranes and increases the cyclic AMP content of the cells. This increase in cyclic AMP then stimulates protein kinase activity, which in turn activates the hormone-sensitive lipase and stimulates lipolysis. However, we attended to the role of endogenous lipid droplets of fat cells and demonstrated that lipolysis induced by catecholamines on fat cells might be dependent on endogenous lipid droplets (15-17). Our data suggest that hormone sensitive lipase protein translocation from the cytosol to the lipid droplets (not activate hormone sensitive lipase) and changes in the physicochemical character of the endogenous lipid droplet surfaces may play

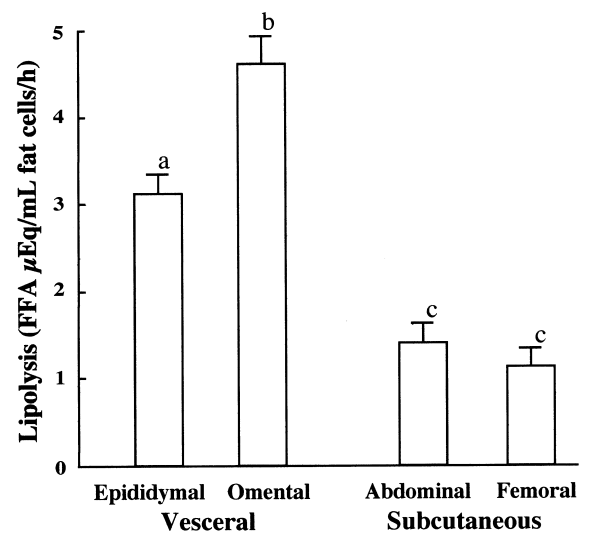

Fig. 6. Lipolysis induced by segment wall extract from Satsuma mandarin orange in rat visceral (epididymal and omental) and subcutaneous (abdominal and femoral) fat cells. $50 \mu \mathrm{L}(10 \mathrm{mg}$ dry material) of segment wall extracts were incubated with fat cells. The results are expressed as mean $\pm S E$ of four experiments. Values not sharing a letter are significantly different, $p<0.05$.

important roles in the lipolysis in fat cells induced by catecholamines. One reason for this demonstration is our sonication experiment; sonication of fat cells caused an increase in lipolysis in the absence of lipolytic stimulants and loss of catecholamine responsiveness. The lipolysis induced by the segment wall extract from Satsuma mandarin orange may also be dependent on the substrate, endogenous lipid droplets, because the lipolytic induction by the extract was lost by sonication of fat cells (data not shown). Further studies are needed to clarify the lipolytic mechanism of the segment wall extract from Satsuma mandarin orange.

Next we examined the lipolysis induced by the extract of the segment wall from Satsuma mandarin orange in rat visceral (epididymal and omental) and subcutaneous (abdominal and femoral) fat cells. As shown in Fig. 6 , the lipolysis induced by the segment wall extract was considerably higher in the visceral fat cells when compared to the subcutaneous fat cells. The $\beta$-antagonist, propranolol, at a concentration $10^{-5} \mathrm{M}$ completely inhibited the lipolysis in visceral or subcutaneous fat cells, whereas the $\alpha$-antagonist, phenoxybenzamine, did not inhibit the lipolysis up to $10^{-3} \mathrm{M}$ in the either type of fat cells (data not shown).

Obesity is a major health problem facing the developed and developing world. Visceral fat accumulation is a particular risk factor for disease such as hyperlipidemia, coronary artery disease, hypertension and type 2 diabetes (18-20). Many dietary supplements have been on sale for weight loss. Citrus aurantium extracts have been introduced for anti-obesity treatment in view of their composition in adrenergic amines $(4,5)$. In this paper, we discovered that other ripe citrus fruits also contained adrenergic amines and stimulated lipolysis in fat cells (Fig. 4), and the segment wall of citrus fruit is a good candidate for anti-obesity treatment because it contains adrenergic amines and stimulates lipolysis in fat cells, especially visceral fat cells. The segment wall 
from citrus fruit is an edible fraction and is generated in large quantities as a waste product during the squeezing of citrus fruits. Furthermore, the segment wall contains dietary fibers such as pectin. We previously reported that citrus pectin inhibited pancreatic lipase activity and reduced lipid adsorption (21). It is well known that pectin lowers plasma and liver cholesterol in several animals and humans (22-25). Therefore, the use of the citrus segment wall as a safe and inexpensive functional food adds potential value to citrus processing.

In conclusion, this investigation suggests that the segment wall from ripe citrus fruits such as Satsuma mandarin orange might exert an anti-obesity effect by stimulating lipolysis, by reducing fat cells in size, and by inhibiting pancreatic lipase activity and reducing lipid adsorption. Therefore, the citrus segment wall may be useful as a potential additive to foods, as a fat-reducing material.

\section{REFERENCES}

1) Moro CO, Basile G. 2000. Obesity and medicinal plants. Fitoterapia 71: S73-S82.

2) Fugh-Berman A, Myers A. 2004. Citrus aurantium, an ingredient of dietary supplements marketed for weight loss: Current status of clinical and basic research. Exp Biol Med 229: 698-704.

3) Bent S, Padula A, Neuhaus J. 2004. Safety and efficancy of Citrus aurantium for weight loss. Am J Cardiol 94: 1359-1361.

4) Pellati F, Benvenuri S, Mlegari M, Firenzouoli F. 2002. Determination of adrenergic agonists from extracts and herbal products of Citrus aurantium L. var. amara by LC. J Pharm Biomed Anal 29: 1113-1119.

5) Carpéné C, Galitzky J, Fontana E, Atgié C, Lafontan M, Berlan M. 1999. Selective activation of $\beta 3$-adrenoceptors by octopamine: comparative studies in mammalian fat cells. Naunyn Schmiedebergs Arch Pharmacol 359: 310-321.

6) Calapai G, Firenzuoli F, Saitta A, Squadrito F, Arlotta MR, Costantino G, Inferrera G. 1999. Antiobesity and cardiovascular toxic effects of Citrus aurantium extracts in the rat: a preliminary report. Fitoterapia 70: 586592.

7) Chen RF. 1967. Removal of fatty acid from serum albumin by charcoal treatment. J Biol Chem 242: 173-181.

8) Rodbell M. 1964. Metabolism of isolated fat cells. J Biol Chem 239: 375-380.

9) Tsujita T, Okuda H. 1983. Carboxylesterases in rat and human sera and their relationship to serum aryl acylamidases and cholinesterases. Eur J Biochem 133: 215220.
10) Hazz S, Fontaine KR, Cutter G, Limdi N, PerumeanChaney S, Allison DB. 2006. Citrus aurantium and synephrine alkaloids in the treatment of overweight and obesity: an update. Obes Rev 7: 79-88.

11) Gougeon R, Harrigan K, Tremblay JF, Hedrei P, Lamarche M, Morais JM. 2005. Increase in the thermic effect of food in women by adrenergic amines extracted from Citrus aurantium. Obes Res 13:1187-1194.

12) Tanaka T. 1954. Species Problems in Citrus, 152 pp. Japan Soc Promotion Sci, Tokyo.

13) Belfrage $P$, Fredrikson G, Strålfors $P$, Toronquist $H$. 1984. Adipose tissue lipases. In: Lipase (Borgström B, Brockman HL, eds), p 365-416. Elsevier, Amsterdam.

14) Yeaman SJ. 1990. Hormone-sensitive lipase-a multipurpose enzyme in lipid metabolism. Biochim Biophys Acta 1052: 128-132.

15) Okuda H, Morimoto C, Tsujita T. 1994. Role of endogenous lipid droplets in lipolysis in rat adipocytes. J Lipid Res 35: 36-44.

16) Morimoto C, Kameda K, Tsujita T, Okuda H. 2001. Relationships between lipolysis induced by various lipolytic agents and hormone-sensitive lipase in rat fat cells. $J$ Lipid Res 42: 120-127.

17) Morimoto C, Tsujita T, Sumida M, Okuda H. 2000. Substrate-dependent lipolysis induced by isoproterenol. Biochem Biophys Res Commun 274: 631-634.

18) Bergman RN, Kim SP, Catalano KJ, Hsu IR, Chiu JD, Kabir M, Hucking K, Ader M. 2006. Why visceral fat is bad: mechanisms of the metabolic syndrome. Obesity 14 (Suppl 1): 16S-19S.

19) Wajchenberg BL. 2000. Subcutaneous and visceral adipose tissue: their relation to the metabolic syndrome. Endoc Rev 21: 697-738.

20) Matsuzawa Y. 1997. Pathophysiology and molecular mechanisms of visceral fat syndrome: the Japanese experience. Diabetes Metab Rev 13: 3-19.

21) Tsujita T, Sumiyoshi M, Han L-K, Fujiwara T, Tsujita J, Okuda H. 2003. Inhibition of lipase activities by citrus pectin. J Nutr Sci Vitaminol 49: 340-345.

22) Hexeberg S, Hexeberg E, Willumsen N, Berge PK. 1994. A study on lipid metabolism in heart and liver of cholesterol- and pectin-fed rats. Br J Nutr 71: 181-192.

23) Tinker LE, Davis PA, Schneeman BO. 1994. Prune fiber or pectin compared with cellulose lower plasma and liver lipds in rats with diet-induced hyperlipidemia. J Nutr 124: 31-40.

24) Shen H, He L, Price RL, Fermandez ML. 1998. Dietary soluble fiber lowers plasma LDL, cholesterol concentrations by altering lipoprotein metabolism in female guinea pigs. J Nutr 128: 1434-1441.

25) Brown L, Rosner B, Willett WW, Sacks FM. 1999. Cholesterol-lowering effects of dietary fiber: a meta-analysis. Am J Clin Nutr 69: 30-42. 